\title{
Correction to: Burst Out of the Dead Land by the Help of Spirituality: A Case Study of Living with Blindness and Cancer
}

\author{
Seyed Hamid Seyed Bagheri ${ }^{1} \cdot$ Mahlagha Dehghan $^{2}$ • \\ Seyyed Hamidreza Alavi ${ }^{3}$ - Sedigheh Iranmanesh ${ }^{2}$ Hadi Khoshab ${ }^{4}$
}

Published online: 16 January 2018

(C) Springer Science+Business Media, LLC, part of Springer Nature 2018

\section{Correction to: J Relig Health (2017) 56:896-906 https://doi.org/10.1007/s10943-016-0284-x}

In the original version of this article, there is a typo in the family name of the author. The co-author family name should be Seyed Bagheri; instead, it has been published as Seyed bagheri.

The original article can be found online at https://doi.org/10.1007/s10943-016-0284-x.

\section{Mahlagha Dehghan \\ m_dehghan86@yahoo.com}

Seyed Hamid Seyed Bagheri

hamidsiba@gmail.com

Seyyed Hamidreza Alavi

hralavi@uk.ac.ir

Sedigheh Iranmanesh

S_iranmanesh@kmu.ac.ir

Hadi Khoshab

Hadikhoshab@gmail.com

1 School of Nursing and Midwifery, Rafsanjan University of Medical Sciences, Rafsanjan, Iran

2 Nursing Research Center, Kerman University of Medical Sciences, Kerman, Iran

3 Department of Educational Sciences, School of Humanities and Letters, Shahid Bahonar University of Kerman, Kerman, Iran

4 Zeinab School of Nursing and Midwifery, Bam University of Medical Sciences, Bam, Iran 